\title{
CONGENITAL ESOPHAGEAL STENOSIS IN AN INFANT
}

Aditya Pratap Singh ${ }^{1}$, Javed Salam Ansari², Pradeep Gupta ${ }^{3}$, Pramila Sharma ${ }^{4}$, R. B. Goyal ${ }^{5}$

\section{HOW TO CITE THIS ARTICLE:}

Aditya Pratap Singh, Javed Salam Ansari, Pradeep Gupta, Pramila Sharma, R. B. Goyal. "Congenital Esophageal Stenosis in an Infant". Journal of Evolution of Medical and Dental Sciences 2014; Vol. 3, Issue 38, August 25; Page: 9820-9823, DOI: 10.14260/jemds/2014/3271

ABSTRACT: Congenital esophageal stenosis is a rare entity with a frequently delayed diagnosis. Patients are often treated according to diagnosis of GERD until intolerance to semisolid diet appears and CES is suspected. It usually presents in infancy and childhood. We are reporting a case of congenital esophageal stenosis in twenty-one days old male child. It is very rare to diagnose congenital esophageal stenosis at this age.

KEYWORDS: congenital esophageal stenosis, CES, GERD.

INTRODUCTION: Congenital esophageal stenosis is a rare disorder. It is characterized by narrowing of esophageal lumen. Patients usually present with post prandial vomiting and cough during feeding, therefore it was considered as one of the differential diagnosis. These symptoms usually appear immediately after food intake and confused with gastro-esophageal reflux disease. There are three types of CES: fibro muscular, membranous and tracheobronchial remnants. Management depends on histological confirmation of CES. It must be differentiated from poor feeding technique, reflux disease, esophagitis, achalasia and intolerance to milk protein. Upper GI dye study should be done and it is confirmed by endoscopy. We are reporting such a rare case. In our knowledge this is an earliest presentation of CES.

CASE HISTORY: A male child 21 days old admitted in our institution with complaints of recurrent postprandial vomiting and cough since birth. He was the product of a second, full term gestation normal vaginal delivery. Baby was born with a birth weight of $2.5 \mathrm{~kg}$. The infant was treated for gastroesophageal reflux and milk intolerance. Patient had an attack of bronchial aspiration with cyanosis, flaccidity and apnea. He was admitted in hospital and diagnosed with GERD and discharged with cisapride and antireflux formula.

Patient was again admitted with same complaints, so this time diagnosis was made as milk protein intolerance or poor feeding technique. Patient was discharged with explanation of correct feeding technique. Ranitidine and domperidone was added as additional treatment along with antireflux measure, slow feedings and a change to soy and elemental formulas (nutamigen).

His diet was based on mother's milk. In spite of all treatment patients complaints were not relieved. He presented with five episodes of vomiting in 24 hour prior to being admitted. For this reason, an esophagogram was performed which was suggestive of? H type fistula then endoscopy was performed to confirm the findings. Endoscopy showed concentric narrowing at mid and lower end of esophagus reducing the lumen close to $5 \mathrm{~mm}$ diameter. No fistulous tract was seen above the stricture.

All blood investigation results were in normal limits. Chest x-ray was suggestive of bilateral mild pneumonitis. Manometric study was not available in our institute so it was not done. Manometric study is very useful in this type of case. There was no history of inherited significant or 
pathological problems associated with her condition. Using guide wire and bougie stricture was dilated. No attempt made to negotiate the stricture to minimize complication. Post dilatation upper GI dye study was performed which was normal. Patient discharged and advised for repeat dilatation after 2 weeks.

DISCUSSION: The incidence of congenital esophageal stenosis is estimated at 1:23,000 to 50,000 live births. ${ }^{1}$ Esophageal stenosis in children is commonly caused by congenital malformation, gastroesophageal reflux and achalasia. CES is a rare, accounting for only $4 \%$ of all cases of esophageal stenosis.

The incidence rate of CES with esophageal atresia or trachea-esophageal fistula varies from $0.4 \%$ to $14 \% .^{3,4}$ It might be beneficial to get a biopsy from the distal esophageal segment during the repair of trachea-esophageal fistula to rule out associated congenital esophageal stenosis.

The reported incidence of associated congenital anomalies ranges from 16 to 33\%.1, 2 CES may be defined as an intrinsic stenosis of the esophagus which is caused by congenital malformation of the esophageal wall architecture. ${ }^{3}$

There are 3 pathologic types of CES: tracheobronchial remnant (TBR), fibro muscular stenosis (FMS) and membranous stenosis. ${ }^{3}$ Tracheo bronchial type is thought to be a developmental disorder in the formation and separation of the premature fore gut into the trachea and esophagus. Membranous diaphragm is exceedingly rare.

It is produced by incomplete reformation of the esophageal lumen upon recanalization of the esophagus observed in the sixth to eight week of gestation. It is difficult to differentiate CES from achalasia and secondary esophageal stenosis, especially stricture caused by reflux esophagitis. ${ }^{4}$

The diagnosis of CES is usually difficult to make on clinical grounds only. Because of the rarity of CES and an unawareness of many pediatricians about the pathology, many patients are presenting relatively late.

Upper gastrointestinal study of infants and children who have repeated vomiting and dysphagia after starting solid food provides the most reliable information. Endoscopic examination usually identifies the cause of stenosis and may rule in/out the presence of the other esophageal lesions.

In our case upper GI study was inconclusive so endoscopy was done. Likewise both the 24 hour $\mathrm{p}^{\mathrm{H}}$ monitoring and esophageal motility studies may be needed to exclude the GERD. Endosonography to provide detailed information of the esophageal wall that enabled the surgeon to determine the optimal intervention in the pediatric age group.

Video manometry is another recently developed technique that permits the simultaneous recording of the intraluminal pressure and dynamic changes in fluoroscopic images. The ideal therapeutic strategy remains controversial.

Current consensus opinion is that less invasive methods as bougienage or balloon dilatation can be used instead of surgery.5,6 Although repeated dilatation may result in significant complications. ${ }^{7,8}$ Balloon dilatation has been considered the treatment of choice in cases of MS.

Balloon dilatation was reported to be more effective and safer than bougienage. With balloon dilatation, expanding force is transmitted only to the stenotic segment of the esophagus and correct placement of the balloon can be determined by direct endoscopic visualization. TBR forms has tendency to resist conservative treatment. ${ }^{4}$ 
TBR must be treated by surgical excision, either by resection of stenotic region followed by end to end anastomosis or by enucleation of the cartilagenous remnants. A complete resection of the stenotic segment and anastomosis has been a reliable treatment, However resection and anastomosis of full esophageal wall may have risk of leakage or restenosis at the anastomotic site.

Esophageal dilatation is not without complications. Esophageal perforation, aspiration pneumonia and cardiac arrest are reported after dilatation. ${ }^{7}$ Surgical intervention should be considered when sufficient dilatation is not achieved. If dilatation required within 6 months intervals and remain ineffective after 3 years, surgical intervention should be undertaken.

Myotomy is another way of surgical treatment. The use of myotomy for FMS is still unclear. Esophageal perforation developed after myotomy has been reported. Circular myotomy has been reported and allowed extirpation of the cartilage segment in esophageal wall and disarrangement of the muscular layer of the esophagus. Other opinion of the surgical management is by thoracoscopy which eliminate thoracotomy.

CONCLUSION: Congenital esophageal stenosis is rare diagnosis in infant. It should be excluded in patient who comes with complaint of cough and postprandial vomiting. Patient with these complaints should have upper GI dye study. Pediatrician and surgeon must be aware about this disorder. In our case diagnosis is made at infancy which is at very early age.

\section{REFERENCES:}

1. Rowe MI, O’Neill JA, Grosfeld JL, et al: Essentials of Pediatric Surgery. St Louis, MO, Mosby YearBook, 1995; 959-961.

2. Neilson IR, Croitoru DP, Guttman FM, et al: Distal congenital esophageal stenosis associated with esophageal atresia. J Pediatr Surg 1991;26:478-482.

3. Nihoul-Fekete C, Backer a De, Lortat-Jacob S, et al: Congenital esophageal stenosis. A review of 20 cases. Pediatr Surg Int 1987; 2: 86-92.

4. Amae S, Nio M, Kamiyama T, et al: Clinical characteristics and management of congenital esophageal stenosis: A report on 14 Cases. J Pediatr Surg 2003; 38: 565-570.

5. Shorter NA, Mooney DP, Vaccaro TJ, et al: Hydrostatic balloon dilation of congenital esophageal stenoses associated with esophageal atresia. J Pediatr Surge 2000; 35: 1742-1745.

6. Diab N, Daher P, Ghorayeb Z, et al: Congenital esophageal stenosis. Eur J Pediatr Surg 1999; 9:177-181.

7. Kawahara H, Imura K, Yagi M, et al: Clinical characteristics of congenital esophageal stenosis distal to associated esophageal atresia. Surgery 2000; 129: 29-38.

8. Lisy J, Hetkova M, Snajdauf J: Long-term outcomes of balloon dilatation of esophageal stricture in children. Acad Radiol 1998; 5: 832-835. 


\section{CASE REPORT}

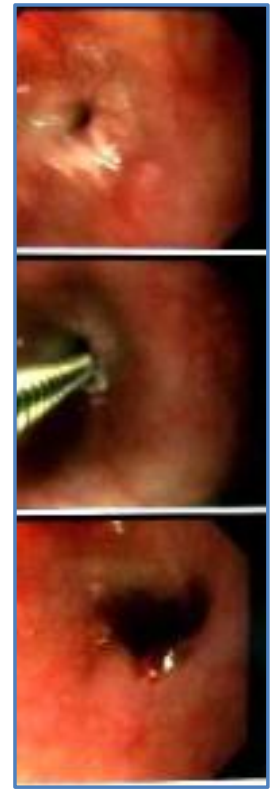

Fig. 1: Endoscopic finding of oesophageal stenosis

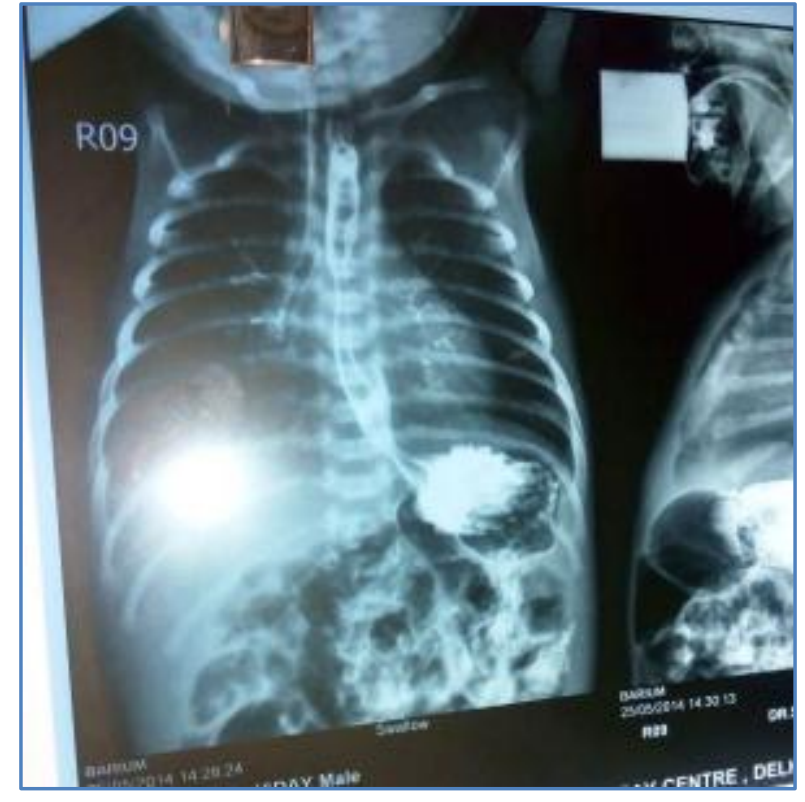

Fig. 2: Post dilatation upper GI dye study

\section{AUTHORS:}

1. Aditya Pratap Singh

2. Javed Salam Ansari

3. Pradeep Gupta

4. Pramila Sharma

5. R. B. Goyal

\section{PARTICULARS OF CONTRIBUTORS:}

1. Resident, Department of Pediatric Surgery, SMS Medical College, Jaipur.

2. Resident, Department of Pediatric Surgery, SMS Medical College, Jaipur.

3. Resident, Department of Pediatric Surgery, SMS Medical College, Jaipur.

4. Assistant Professor, Department of Pediatric Surgery, SMS Medical College, Jaipur.
5. Professor and HOD, Department of Pediatric Surgery, SMS Medical College, Jaipur.

\section{NAME ADDRESS EMAIL ID OF THE CORRESPONDING AUTHOR:}

Dr. Aditya Pratap Singh,

Near The Mali Hostel,

Main Bali Road,

Falna District, Pali,

Rajasthan.

Email: dr.adisms@gmail.com

Date of Submission: 08/08/2014.

Date of Peer Review: 09/08/2014.

Date of Acceptance: 20/08/2014.

Date of Publishing: 25/08/2014. 